Canadian

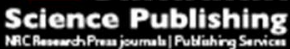

Canadian Geotechnical Journal Revue canadienne de géotechnique

\title{
Reactive Transport of Chemicals in Unsaturated Soils: Numerical Model Development and Verification
}

\begin{tabular}{|r|l|}
\hline Journal: & Canadian Geotechnical Journal \\
\hline Manuscript ID: & cgj-2014-0436.R1 \\
\hline Manuscript Type: & Note \\
\hline Complete List of Authors: & $\begin{array}{l}\text { Sedighi, Majid; Cradiff University, Geoenvironmental Research Centre, } \\
\text { School of Engineering } \\
\text { Thomas, Hywel Rhys; Cardiff University, Geoenvironmental Research } \\
\text { Centre, School of Engineering } \\
\text { Vardon, Philip; Delft University of Technology, Geo-Engineering Section }\end{array}$ \\
\hline Keyword: & $\begin{array}{l}\text { Reactive transport, Coupled modelling, Unsaturated soil, Geochemical, } \\
\text { PHREEC }\end{array}$ \\
\hline \multicolumn{2}{|c}{} \\
\hline
\end{tabular}

SCHOLARONE ${ }^{m}$

Manuscripts 


\title{
Reactive Transport of Chemicals in Unsaturated Soils: Numerical Model Development and Verification
}

\author{
Majid Sedighi ${ }^{1,2^{*}}$, Hywel R. Thomas ${ }^{1}$ and Philip J. Vardon ${ }^{1,3}$ \\ ${ }^{1}$ Geoenvironmental Research Centre, School of Engineering, Cardiff University, The \\ Queen's Buildings, The Parade, Cardiff, CF24 3AA, United Kingdom. \\ ${ }^{2}$ School of Mechanical, Aerospace and Civil Engineering, Faculty of Engineering, The \\ University of Manchester, Sackville Street, Manchester, M1 3BB, United Kingdom \\ (Current address) \\ ${ }^{3}$ Section of Geo-Engineering, Delft University of Technology, PO Box 5048, 2600 GA, Delft, \\ The Netherlands (Current address) \\ *Corresponding Author (majid.sedighi@manchester.ac.uk)
}

\begin{abstract}
This paper presents the development of a numerical model for reactive transport of multicomponent chemicals in unsaturated soils. The model has been developed based on a coupled thermal, hydraulic, chemical and mechanical formulation and extended by the inclusion of geochemical processes under mixed equilibrium and kinetically controlled reactions in/between the solid, aqueous and gas phases in soil. This has been achieved by coupling the transport model (COMPASS) with the geochemical model PHREEQC.
\end{abstract}

Key coupling between the geochemical modelling and flow of chemicals has been established via the inclusion of porosity modification from mineral precipitation/dissolution reactions and the consequential effects on flow processes. Verification of the developed model is addressed via a series of benchmark simulations with a focus on testing the coupling between the transport model and geochemical model. Good results have been achieved for the verification of the theoretical and numerical implementation of the new developments in the model. A simulation is presented to demonstrate the effects of mineral reactions on porosity evolution and chemical diffusion in a low porosity soil. The model developed is an advanced tool for studying the hydro-geochemical 
processes in unsaturated soils under variable thermal, hydraulic, chemical and mechanical (THCM) conditions.

\section{Keywords}

Reactive transport, Coupled modelling, THCM, Geochemical, Unsaturated soil, PHREEQC. 


\section{Introduction}

Reactive transport of chemicals in soil includes chemical transport processes and geochemical reactions which can involve multiple, homogenous and heterogeneous chemical reactions. In many geoenvironmental problems, hydro-geochemical processes are coupled with physical, chemical and mechanical effects (e.g. compacted clay as the buffer candidate for geological disposal of high level radioactive waste). Studying such conditions requires advanced conceptual and theoretical models, comprising multiphase, multicomponent transport processes and various geochemical reactions. Changes in the environmental conditions, e.g. water content, water chemical composition and temperature, can alter the chemical equilibrium conditions of the system and trigger chemical reactions between the chemical components, i.e. clay minerals, accessory minerals and ionic species.

Computational modelling of the reactive transport of multicomponent chemicals in soil has advanced over the last few decades. Most of the models developed have adopted theoretical advances in chemical transport and geochemical/biogeochemical modelling. The developed approaches have been mainly based on coupling the chemical transport models with external geochemical models using operation-splitting schemes (e.g. Prommer, 2002; Jacques and Šimůnek, 2005; Seetharam et al. 2007; Guimarães et al. 2007; Samper et al. 2009). These approaches are based on splitting the solution to i) solving the partial differential equations of the transport formulations and ii) solving the non-linear algebraic or partial differential equations representing the equilibrium or kinetically controlled chemical reactions. Approaches such as the sequential iterative $(\mathrm{SIA})$, sequential non-iterative (SNIA) and sequential partly-iterative (SPIA) have been suggested and applied successfully to achieve such solution to the reactive transport formulation (Steefel and MacQuarrie, 1996; Samper et al. 2009).

The geochemical model PHREEQC (Parkhurst and Appelo 1999) is among the models that have received the most interest in developing such coupled models. Prommer (2002) presented a computer code PHT3D by coupling MODFLOW/MT3DMS for the hydraulic and chemical transport 
calculations and PHREEQC version 2 (Parkhurst and Appelo 1999) for the chemical reactions. A reactive transport model was presented by Jacques and Šimůnek (2005) for modelling the reactive transport and biogeochemical processes in variably-saturated porous media (HP1) which is a result of coupling the water and solute transport model HYDRUS-1D (Šimůnek et al. 2008) and PHREEQC version 2. Wissmeier and Barry (2008) presented a one-dimensional flow and solute transport model in the unsaturated medium by implementing the moisture-based form of Richard's equation into the geochemical modelling framework PHREEQC.

This paper presents the development of a numerical model for studying hydro- geochemical processes in unsaturated soils based on a coupled thermal, hydraulic, chemical and mechanical formulation (THCM). The theoretical advances in both transport of chemicals and geochemical reactions have been included in the model. The emphasis in this paper is to present the coupling of key geochemical processes implemented within the existing THCM model. The development has aimed at providing a more comprehensive coupled THCM model which includes geochemical reactions for studying the behaviour of unsaturated soils and especially compacted clays. The model has been built based on an existing THCM numerical model (COMPASS) developed by Thomas and co-workers (e.g. Thomas and He 1998; Seetharam et al. 2006; Sedighi et al. 2011; Thomas et al. 2012). Extended theoretical formulations of multicomponent chemical transport (Sedighi 2011; Thomas et al. 2012) have been included in the model.

Inclusion of geochemical features through coupling the PHREEQC (version 2.15) model with the extended THCM model is presented in this paper. The main focus in this paper is to provide the verifications and preliminary applications related to the development of COMPASS-PHREEQ. Combined with the description of the theoretical aspects of the model, presented by Thomas et al. (2012), this paper provides an adequate description of the model development. A series of benchmarks have been defined and simulations have been carried out in order to test the theoretical and numerical implementations in the new model. Additionally, a number of coupling 
features between chemistry and flow behaviour has been established in the model. This includes the geochemical reaction feedback to porosity and flow properties. The effects of mineral precipitation and its feedback on porosity and diffusion properties will be also demonstrated via an application of the model which deals with the diffusion of chemicals in a low porosity system.

\section{Theoretical formulations and computational aspects}

The processes considered in the coupled THCM formulation of the model are as follows: i) heat transfer via mechanisms of conduction, convection and latent heat of vaporisation, ii) moisture transfer including water and vapour flow due to various driving potentials, iii) transfer of gas phase or air, iv) transport of multicomponent chemicals present in the liquid phase, v) geochemical reactions including heterogeneous and homogenous reactions between/in solid, liquid and gas phases and vi) deformation behaviour which is based on stress-strain equilibrium, considering appropriate constitutive relationships describing the behaviour of unsaturated soil. Detailed description of the coupled THM formulation can be found elsewhere (e.g. Thomas and He 1998).

The formulations of the reactive transport of chemicals in liquid are expressed based on a mass conservation law. Based on the work presented by Seetharam et al. (2007), geochemical reactions that may occur in the system causing loss or gain of each component are considered via a sink/source term in the transport formulation. The transport formulation considers the advective, diffusive and dispersive transport of multiple chemicals in the liquid phase. A formulation of the diffusion of multiple ionic species has been developed and implemented in the model which incorporates the electrochemical and thermal potentials in the flow (Sedighi et al. 2011; Thomas et al. 2012). The new theoretical developments enable the modelling of multiple ionic systems under combined chemical and thermal gradients considering the overall electro-neutrality of the aqueous system (Sedighi 2011; Thomas et al. 2012). In other words, the overall electrical neutrality of the system has been considered as an additional constraint to the mass conservation equation. 
The formulation of the reactive transport of chemicals is presented as (Sedighi et al. 2011; Thomas et al. 2012):

$$
\frac{\partial\left(\theta_{l} c_{i} \delta V\right)}{\partial t}+\frac{\partial\left(\theta_{l} s_{i} \delta V\right)}{\partial t}=-\delta V \nabla \cdot\left(c_{i} \mathbf{v}_{l}-\sum_{j=1}^{n_{c}} \theta_{l} \tau_{i} D_{i j} \nabla c_{j}-\theta_{l} \tau_{i} D_{i}^{T} \nabla T-\mathbf{D}_{m} \nabla c_{j}\right)
$$

where, $\theta_{l}$ is the volumetric liquid content. $c_{i}$ is the concentration of the $i^{\text {th }}$ chemical component in the liquid phase. $t$ is time and $\delta V$ represents the incremental volume. $s_{i}$ is a geochemical sink/source term which stands for the amount of the $i^{\text {th }}$ chemical component which is produced or depleted due to geochemical reactions. $\mathbf{v}_{1}$ represents the water velocity and the major driving potentials for moisture flow include capillary potential, gravitational potential and osmotic potential. $D_{i j}$ is the effective molecular diffusion coefficient of the $i^{\text {th }}$ chemical due to the chemical gradient of the $j^{\text {th }}$ component, $D_{i}^{T}$ represents the thermal diffusion coefficient of the $i^{\text {th }}$ chemical and $\mathbf{D}_{m}$ is the matrix of the effective dispersion coefficients (Seetharam et al. 2007). $\tau_{i}$ is the tortuosity factor of the $i^{\text {th }}$ chemical component.

The molecular diffusion and thermal diffusion coefficients in ionic systems can be presented as (Sedighi et al., 2011; Thomas et al. 2012):

$$
\begin{gathered}
D_{i j}=-\delta_{i j} D_{i}^{0}\left(1+\frac{\partial \ln \gamma_{i}}{\partial \ln c_{i}}\right)+\frac{z_{i} D_{i}^{0} c_{i}}{\sum_{k=1}^{n_{c}} z_{k}^{2} D_{k}^{0} c_{k}} z_{j} D_{j}^{0}\left(1+\frac{\partial \ln \gamma_{j}}{\partial \ln c_{j}}\right) \\
D_{i}^{T}=-D_{i}^{0} c_{i} \frac{Q_{i}^{*}}{R T^{2}}+\frac{z_{i} D_{i}^{0} c_{i}}{\sum_{k=1}^{n_{c}} z_{k}^{2} D_{k}^{0} c_{k}} \sum_{j=1}^{n_{c}} z_{j} c_{j} D_{j}^{0} \frac{Q_{j}^{*}}{R T^{2}}
\end{gathered}
$$

where, $\delta_{i j}$ is the Kronecker's delta. $D_{i}^{0}$ represents the self diffusion coefficient of the $i^{\text {th }}$ chemical component in free water, $\gamma_{i}$ is the activity coefficient of the $i^{\text {th }}$ chemical component and $z_{i}$ is valence of the ion. $Q_{j}^{*}$ is the heat of transport.

The components of the geochemical sink/source term presented in the governing equation of chemicals are calculated using a geochemical model PHREEQC version 2 (Parkhurst and Appelo 1999) 
which was linked to the model. PHREEQC version 2 is capable of modelling mixed equilibrium controlled $_{L}$ and kinetically controlled ${ }_{2}$ geochemical reactions. The model was selected as it contains advanced geochemical modelling features such as reactions in equilibrium with fixed-volume or fixed-pressure gas phases, formation/dissolution of ideal, multicomponent or non-ideal, binary solid solutions, kinetically controlled solid-liquid heterogeneous reactions with user-defined rate expressions and capability of calculating the activity coefficients at high concentrations (Parkhurst and Appelo 1999). The following geochemical modelling features have been included in the transport model:

1) Equilibrium reactions, applied to precipitation/dissolution of minerals.

2) Kinetically controlled reactions, applied to precipitation/dissolution of minerals.

3) Ion exchange processes, applied under equilibrium conditions.

The solution adopted for the reactive transport formulation of chemicals is based on a time-splitting approach in which the governing equations for the transport (and mechanical) formulation and the geochemical reactions are solved sequentially. This means that the link between the transport and mechanical model (COMPASS) and geochemical model (PHREEQC) is provided incorporating a sequential non-iterative approach (SNIA). In this approach the chemical transport equations are solved first. The achieved converged value for each node is then transferred to the geochemical code (i.e. once per time-step). The value of chemical concentration and geochemical parameters are then updated. The procedure is repeated for all subsequent time-steps. This approach has proved reasonable as long as the time-step remains small (e.g. Seetharam 2007). Figure 1 presents the SNIA coupling approach and modular data exchange between COMPASS and PHREEQC. As shown in this figure, the initial conditions including geochemical variables are defined first. The governing equations for moisture, heat and chemical flow and deformation are solved until convergence is achieved. The results are then transferred to the geochemical module (PHREEQC) and the outputs in terms of nodal values of dissolved chemicals and geochemical variables are used for next time step 
calculations. In order to accelerate computation, provision has been made to impose a relative tolerance level check for the dissolved chemical concentration (calculated from the transport analysis) and temperature defined as diff1 and diff2, respectively (Figure 1):

$$
\begin{gathered}
\operatorname{diff} 1=\left(c_{i}\right)^{\text {transport }}-\left(c_{i}\right)^{n} \\
\operatorname{diff} 2=(T)^{n+1}-(T)^{n}
\end{gathered}
$$

where $\left(c_{i}\right)^{\text {transport }}$ and $\left(c_{i}\right)^{n}$ are the chemical concentrations of the $\mathrm{i}^{\text {th }}$ component after solving the transport equations at time $\mathrm{n}+1$ and at time $\mathrm{n}$, respectively. $(T)^{n+1}$ and $(T)^{n}$ are temperature values at time $n+1$ and $n$, respectively.

The numerical solution of the formulations of the coupled thermal, hydraulic and mechanical governing equations is based the on the finite element and finite difference methods (Thomas and He, 1998). Further details and discussions on the numerical solution to the coupled THM and THCM formulation of the model have been comprehensively discussed by Thomas and He (1998) and Seetharam et al. (2007).

The transport model (COMPASS) code is written in FORTRAN programming language, while PHREEQC is a $\mathrm{C}$ based coded. The two models were computationally linked together using a crosslink subroutine, written in the C language. In the "cross-link" subroutine, the results of the transport processes are collected first using "pointer" variables. This assists with an efficient and secure data exchange between the two models. Using the cross-link subroutine, the main subroutine of PHREEQC is called and the input data required for the geochemical analysis are exchanged. The formulation of the equilibrium or kinetically controlled chemical reactions is then calculated which provide modified concentrations of all the dissolved chemicals. The outputs are exchanged again using the cross-link subroutine and sent back to the interface module of transport code. It is noted that the time-step of the current transport analysis is transferred to PHREEQC which is applied for calculating the kinetically controlled reactions. 
Mineral precipitation and dissolution during the reactive transport can affect the flow properties due to the alteration of mineral volume during precipitation/dissolution (Steefel and Maher 2009). This can subsequently change the available porosity for the flow. A feedback between mineral precipitation/dissolution, total mineral volume and eventually porosity has been provided under the coupling scheme. The volume of mineral (precipitate as part of the solid phase) is updated from the results of geochemical analysis. As a result of changes in the mineral volume, the porosity varies and the flow parameters including hydraulic conductivity and tortuosity factor may change. The resultant concentrations of minerals calculated from the equilibrium precipitation and dissolution reactions or kinetically controlled reactions are used to calculate the total amount of volume related to the precipitation/dissolution process by knowing the concentration of the solid phase and its molar volume at each time-step. The mineral volume for each node is then updated after the geochemical reaction step. The porosity is then modified for each integration point in an element (in relation to the finite element solution) where the hydro/chemical flow properties, such as hydraulic conductivity or diffusion coefficient, are evaluated in the model.

Following Steefel and Lasaga (1994), the permeability variation caused by a change in porosity can be simplified based on the Kozeny-Carmen equation. The hydraulic conductivity can therefore be calculated from the changes of porosity due to mineral precipitation or dissolution, given as:

$$
\frac{\left(K_{l}\right)_{2}}{\left(K_{l}\right)_{1}}=\left(\frac{n_{2}}{n_{1}}\right)^{3}
$$

where, $\left(K_{l}\right)_{1}$ and $\left(K_{l}\right)_{2}$ are the intrinsic permeability values of the soil before and after the geochemical reactions, respectively. $n_{1}$ and $n_{2}$ are the porosity of the soils before and after the geochemical reactions, respectively.

\section{Verification of the coupled COMPASS-PHREEQC model}

The accuracy of the implementation of theoretical formulations and the numerical scheme adopted for coupling the two models has been tested based on a series of verification benchmarks. The 
verification of transport model for multicomponent chemical transport has been presented in detail by Sedighi (2011) and Thomas et al. (2012). The coupling between the chemical transport model (COMPASS) and the chemical reaction model (PHREEQC) is examined for the geochemical features implemented.

\subsection{Chemical transport with mineral precipitation/dissolution reaction - Test I}

The transport process coupled with a mineral precipitation and dissolution reaction front has been tested using a benchmark presented by $\mathrm{Xu}$ and Pruess (1998). The studied system is onedimensional transport of two hypothetical species, namely $A^{+}$and $B^{-}$that originate from the dissolution of a mineral phase $A B_{s}$ (i.e., $\left.A B_{s}=A^{+}+B^{-}\right)$. The reactive transport of a binary solution, under i) equilibrium mineral precipitation/dissolution and ii) kinetically controlled mineral reactions are studied here. The results of three series of simulations are presented which include:

Test I-a: The transport of two hypothetical species (by advection and dispersion mechanisms) with mineral precipitation and dissolution under equilibrium chemical reaction. The results are compared with those obtained from the analytical solution presented by Xu and Pruess (1998) for the same problem.

Test I-b: The transport of two hypothetical species (Only by advection) with mineral precipitation and dissolution under kinetics at steady state condition. The results are compared with those obtained from the analytical solution provided by Xu and Pruess (1998) for the same conditions.

Test I-c: The transport of two hypothetical species (by advection and dispersion mechanisms) with mineral precipitation and dissolution under both equilibrium and kinetically controlled reactions. In this series of simulations, several rates of reactions have been used. The results of numerical simulations under equilibrium chemical reaction are compared with those obtained by considering different rates for the kinetics of reaction. 
It is noted that diffusion of chemicals was not considered in these tests. The dispersion is described as a longitudinal dispersion for $1 \mathrm{D}$ transport. The system considered is a $1 \mathrm{~m}$ saturated domain under a steady flow of a solution from one boundary (constant flux). The domain initially contained same concentrations of $A^{+}$and $B^{-}$components $\left(0.1 \mathrm{~mol} / \mathrm{m}^{3}\right)$. The injection solution contains the same concentration of chemical $B^{-}$as in the domain $\left(0.1 \mathrm{~mol} / \mathrm{m}^{3}\right)$ and a different concentration of the other component $\mathrm{A}^{+}\left(0.01 \mathrm{~mol} / \mathrm{m}^{3}\right)$ compared with the initial amount in the domain. The concentrations of ionic chemicals were considered to be relatively low, therefore, the ionic activity can be assumed equal to the concentration and the activity modification factor can be ignored in the calculations. The porosity and pore velocity of the study domain were considered to be 0.4 and 0.1 $\mathrm{m} /$ day, respectively. A fixed pore water pressure was considered at the boundary to provide the constant pore velocity required. Table 1 provides a summary of the material properties and parameters used in the simulations.

The equilibrium constant of the reaction was assumed to be $10^{-8}$. Following Xu and Pruess (1998), a first-order kinetic rate of reaction, is considered for the simulations under kinetics, given as:

$$
r_{A B}=k \sigma\left(1-\frac{c_{A} c_{B}}{K_{e q}}\right)
$$

where $k$ represents the kinetic rate constant, $\sigma$ is the specific surface area and $K_{e q}$ is the equilibrium constant of the reaction. $c_{A}$ and $c_{B}$ are the concentrations of species $\mathrm{A}^{+}$and $\mathrm{B}^{-}$, respectively.

It is noted that in the simulation based on kinetically controlled condition, dispersion coefficient was set to zero, providing a pure advective flow (i.e. Test I-b). For test I-b, the kinetic rate constant is assumed to be $2 \times 10^{-10} \mathrm{~mol} \cdot \mathrm{s}^{-1} \mathrm{~m}^{-2}$. The specific surface area was considered to be equal to $1.0 \mathrm{~m}^{2} / \mathrm{l}$.

The domain was discretised into 100 equally-sized 4-noded quadrilateral elements. A variable timestep was considered for the simulation which allows the time-step to be increased or decreased depending on the numerical convergence. The maximum allowable time-step was 3600 seconds. The temperature was fixed in the domain (293 K). 
Figure 2 shows the variation of concentration of chemicals $\mathrm{A}^{+}$and $\mathrm{B}^{-}$in the domain calculated using the numerical model and analytical solution under equilibrium mineral precipitation. In this series of analyses, the dispersion coefficient was assumed to be 0.02 , providing an advective-dispersive flow regime in the domain. The results are presented at five days and indicate a good correlation between the two approaches. The concentration of component $A^{+}$at the boundary is lower than in the solution. Accordingly and in order to maintain the equilibrium between mineral and dissolved components, some mineral has been dissolved in the system which has increased the concentration of component $\mathrm{B}^{-}$compared with the initial level. Therefore, after some time, the re-equilibrated system contains an unequal solution in terms of ionic components $\mathrm{A}^{+}$and $\mathrm{B}^{-}$. However, the equilibrium condition between the mineral content and dissolved chemicals always remains based on the defined equilibrium constant, i.e. $10^{-8}$.

Figure 3 shows the concentration patterns of dissolved chemicals $\mathrm{A}^{+}$and $\mathrm{B}^{-}$in the domain, calculated by the numerical modelling and analytical solution under kinetically controlled condition for mineral precipitation/dissolution at steady state. The results are presented at steady-state in order to compare with the results of the analytical solution. The results of numerical model and analytical solution are well compatible with each other. The results indicate that at steady-state, the concentrations of the dissolved chemicals at the boundary have changed to the concentration of the flushing solution through precipitation of the $A_{s}$ mineral in the domain.

A series of numerical simulations was also performed under different kinetic reaction rates. Different values for the reaction rate constant were assumed including $2 \times 10^{-8}, 2 \times 10^{-9}$ and $2 \times 10^{-10} \mathrm{~mol}^{-1} \mathrm{~s}^{-2}$. The results are also compared with those under equilibrium reaction to demonstrate the effects of the kinetic rate on the results. In this series of analyses, the dispersion coefficient was assumed to be 0.02 , providing an advective-dispersive flow regime in the domain. Figure 4 shows the results of simulations in terms of dissolved chemical concentrations under kinetic with different rates and equilibrium after five days. As expected, with increasing the reaction rate, the concentration profile 
tends to a similar profile resulted under equilibrium precipitation and dissolution reaction at same time (symbols). The results are in agreement with the results of a similar series of simulations reported by Xu and Pruess (1998).

\subsection{Chemical Transport with multiple Precipitation/Dissolution - Test II}

This example aims at testing the reactive transport of ions with multiple precipitation and dissolution reaction that occur during the flow. The verification is based on an example provided by Engesgaard and Kipp (1992). The problem considered is a domain in which an aqueous solution which is in equilibrium with calcite is flushed by a solution with a different chemical composition. This leads to multiple precipitation/dissolution of calcite and dolomite as the solution front progressed.

A two dimensional $0.5 \mathrm{~m}$ (length) $\times 0.1 \mathrm{~m}$ (height) column was considered with a uniform mesh of $0.01 \mathrm{~m}$ long 4-noded quadrilateral elements. Four dissolved ionic components $\left(\mathrm{Cl}^{-}, \mathrm{Mg}^{2+}, \mathrm{Ca}^{2+}\right.$ and $\mathrm{CO}_{3}{ }^{2-}$ ) were considered. The ionic system was considered to be in equilibrium with two minerals namely calcite $\left(\mathrm{CaCO}_{3}=2.2 \times 10^{-5} \mathrm{~mol} / \mathrm{kg}\right.$ soil $)$ and dolomite $\left(\mathrm{CaMg}\left(\mathrm{CO}_{3}{ }^{-2}\right)=0 \mathrm{~mol} / \mathrm{kg}\right.$ soil $)$. The initial concentrations of ionic species are $\mathrm{Cl}^{-}=0, \mathrm{Mg}^{2+}=0, \mathrm{Ca}^{2+}=0.124$ and $\mathrm{CO}_{3}{ }^{2-}=0.124 \mathrm{~mol} / \mathrm{m}^{3}$. At one boundary, fixed concentrations of the dissolved ions were assumed $\left(\mathrm{Cl}^{-}=2.0, \mathrm{Mg}^{2+}=1.0, \mathrm{Ca}^{2+}=0\right.$ and $\mathrm{CO}_{3}{ }^{2-}=0 \mathrm{~mol} / \mathrm{m}^{3}$ ) whilst at the other end, an impermeable chemical boundary was considered. The initial $\mathrm{pH}$ of the system was 9.91 and the $\mathrm{pH}$ of injection fluid was 7.06 . Temperature was fixed at 298 K. A fixed pore water pressure at each boundary was assumed, providing a constant pore water velocity. The system is saturated and porosity was assumed to be 0.32 . The bulk density is considered to be $1,800 \mathrm{~kg} / \mathrm{m}^{3}$. The pore velocity and dispersivity coefficient are $9.37 \times 10^{-6} \mathrm{~m} / \mathrm{s}$ and $0.002 \mathrm{~m}$, respectively. Table 2 presents the physical and chemical properties considered for this exercise. A constant time-step of 200 seconds was used in the simulation, providing a good numerical convergence. 
Figure 5 shows the distribution of ions in the domain at 21,000 seconds after the injection started. The time was selected to compare the results with same simulation, reported by Engesgaard and Kipp, 1992. The numerical model results for calcite and dolomite mineral concentrations are also presented in figure 6. The results of the modelling reported by Engesgaard and Kipp (1992) have been provided in each figure for comparison. Higher concentration of $\mathrm{Mg}^{2+}$ ions and lower $\mathrm{Ca}^{2+}$ ions migrate from the boundary to the domain. To maintain the equilibrium between dissolved chemicals and minerals, calcite is dissolved into the pore fluid, providing more calcium ions whilst dolomite precipitates in the domain. As a result, the concentration of calcium ions varies in the region, affected by dissolution of calcite and precipitation of dolomite. In the area close to boundary, further flushing of the dissolved ions with water, has resulted in dissolution of both minerals. Therefore, both minerals were dissolved completely in the approximately $8 \mathrm{~cm}$ away from the boundary. The results of the numerical simulation and those reported by Engesgaard and Kipp (1992) are in close agreement.

\subsection{Transport multiple ionic species with ionic exchange reactions - Test III}

This section provides a verification test on coupling the ion exchange geochemical reaction under equilibrium with the chemical transport model. This verification has been presented in PHREEQC (Parkhurst and Appelo 1999) as an example simulation and also used by others as a benchmark for testing (e.g. Prommer 2002). The problem consists of an ionic solution which initially contains two minerals namely $\mathrm{NaNO}_{3}$ and $\mathrm{KNO}_{3}$. The system is flushed at a constant discharge rate with a $\mathrm{CaCl}_{2}$ solution from one boundary. The medium has a total cation exchange capacity of $1.1 \times 10^{-3} \mathrm{~mol} / \mathrm{l}$ consisting of both Na-exchanger and K-exchanger. The concentration of the chemicals and composition of the exchanger vary with time when the solution is brought to the equilibrium with the flushed solution with higher concentration of calcium ions.

Five ionic components were considered in the model including $\mathrm{Ca}^{2+}, \mathrm{Cl}^{-}, \mathrm{K}^{+}, \mathrm{Na}^{+}$and $\mathrm{NO}^{3-}$. The exchanger components were considered to be $\mathrm{Na}^{-}, \mathrm{K}^{-}$and $\mathrm{Ca}-\mathrm{X}$, where $\mathrm{X}$ is the exchanger body 
(Parkhurst and Appelo 1999). The initial concentrations of chemicals in the system were $\mathrm{Ca}^{2+}=0, \mathrm{Cl}^{-}$ $=0, \mathrm{~K}^{+}=0.2, \mathrm{Na}^{+}=1.0$ and $\mathrm{NO}^{3-}=1.2 \mathrm{~mol} / \mathrm{m}^{3}$. The initial concentrations of exchangers were $\mathrm{Na}-\mathrm{X}=0.55$, $\mathrm{K}-\mathrm{X}=0.55$ and $\mathrm{Ca}-\mathrm{X}_{2}=0 \mathrm{~mol} / \mathrm{m}^{3}$. The initial $\mathrm{pH}$ was 7.0. At one boundary, fixed concentrations of dissolved ions were assumed whilst at the other end, an impermeable boundary condition was considered. The injection fluid contains only $\mathrm{Ca}^{2+}=0.6 \mathrm{~mol} / \mathrm{m}^{3}$ and $\mathrm{Cl}^{-}=1.2 \mathrm{~mol} / \mathrm{m}^{3}$. The pore velocity and dispersivity were considered to be $1 \mathrm{~m} /$ day and $0.002 \mathrm{~m}$, respectively. A fixed pore water pressure assumed at each boundary provided a constant pore water velocity as required. Table 3 presents the parameters used in the simulation. The analysing domain length is a $0.08 \mathrm{~m}$ domain. The porosity was assumed to be 1.0 , i.e. no solid component. The domain was discretised into 40 elements consisting 4-noded quadrilateral elements. A constant time-step of 90 seconds was considered for the simulation. The simulation was also performed under isothermal condition.

Figure 7 presents the analysed break-through curves for different ionic species in the solution at different pore volumes compared with the results of the modelling using PHREEQC. The results show a close agreement between the two models. When the inlet solution is flushed to the aqueousexchanger system, the composition of exchanger is affected by the replacement of $\mathrm{Ca}^{2+}$ ions in the exchanger and consequently the concentration of aqueous solution changes. Chloride is a conservative ion and arrives in the effluent at approximately 0.5 pore volume. The sodium initially present in the column exchanges with the incoming calcium. This process proceeds as long as the exchanger contains sodium. The midpoint of the breakthrough curve for sodium occurs at about 1.5 pore volumes. Since potassium exchanges more strongly than sodium (larger log $K_{\text {eq }}$ in the exchange reactions), potassium is released after sodium. Finally, when all potassium has been released, the concentration of calcium increases to a steady-state value equal to the concentration of the boundary solution. The simulation results are closely correlated with the results calculated by PHREEQC. This allows demonstrating the correctness of the implementation of the approach adopted for reactive transport under equilibrium ion exchange reaction over this particular benchmark. 


\section{The effects of mineral reactions from porosity feedback on ionic diffusion}

An example simulation is presented which aims to demonstrate the porosity modification feedback from geochemical reaction modelling and the effects on chemical transport properties. This simulation was designed to demonstrate the effects of porosity modification due to mineral precipitation on the diffusion of a binary solution. In the simulation, a saturated low porosity porous medium was considered which initially contains no dissolved chemicals and minerals. The domain was exposed to a super-saturated binary solution at one boundary. The diffusion process is coupled with mineral precipitation. Diffusion of the binary solution through the domain was investigated under the porosity feedback implemented algorithm and without this effect. The feedback between mineral precipitation volume and porosity affects the tortuosity of chemical diffusion which changes the diffusion pattern of chemicals.

The analysed domain considered was $2 \mathrm{D}(0.1 \times 0.1 \mathrm{~m})$ with porosity of 0.05 . The domain was discretised into 100 equally-sized elements consisting 4-noded quadrilateral elements. A variable time-step was used, allowing the variation of time-step depending on convergence. The simulation was performed under isothermal and saturated conditions. Therefore, water pressure and temperature were fixed during the analysis. These assumptions lead to pure isothermal diffusion flow in the domain. Table 4 presents the parameter used for the simulation.

Two ionic components were considered in the model including, hypothetically $A^{+}$and $B^{-}$in equilibrium with $A B$ mineral. At one boundary, fixed concentrations of dissolved ions $\left(25 \mathrm{~mol} / \mathrm{m}^{3}\right)$ are assumed while at the other end, an impermeable boundary condition is assumed. The soil solution contains no chemical initially. The solution at injecting boundary is considered to be supersaturated solution. The tortuosity factor for chemical diffusion is considered via a modified equation, proposed by Millington and Quirk (1961). As a first approximation, the effect of mineral precipitate volume on tortuosity is included as an additional term to the original tortuosity factor proposed by Millington and Quirk (1961) as: 


$$
\tau=\left(\frac{n-n_{m}}{n}\right)\left(\frac{\theta_{l}^{7 / 3}}{n^{2}}\right)
$$

where, $n_{m}$ is the ratio of mineral volume over the soil volume, which is calculated from geochemical interface module in the model.

Due to the equilibrium condition assumed for mineral precipitation, the dissolved chemicals were in equilibrium with the precipitate mineral. Therefore, the concentration of dissolved chemicals did not increase from the value associated with equilibrium reaction condition. In other words, extra amount of dissolved chemicals have been precipitated in the system. Figure 8 presents the variation of mineral concentration with times considering the porosity feedback. The results of simulation with no feedback from mineral precipitation on flow have also provided in Figure 9. As a result of the porosity feedback algorithm implemented in the model, lower amount of minerals has been precipitated compared with the results of simulations without this effect especially in longer duration of analysis. This is due to the effective diffusion coefficient decrease as a result of porosity reduction with mineral precipitation and therefore the amount of dissolved chemicals which diffuse to the system is reduced. This observation is more highlighted in longer simulation times.

Figure 10 shows the transient profiles of the dissolved chemical in the domain, resulted from modelling with and without considering porosity feedback modification. The results indicate that porosity modification from mineral precipitation hinders the diffusion front compared with the simulation without considering porosity feedback. As a consequence of mineral precipitation, the available porosity has decreased due to the accumulated mineral. It implicitly affects the tortuosity factor, reduces the permeability and consequently decreases the rate of migration of chemicals. The reduction of porosity also prevents further mineral precipitation as a result of lower migration rate of dissolved chemicals. Figure 10 also shows the transient profile of the volume of mineral, precipitated in the domain. A comparison is provided with the available initial porosity. The simulations presented in this section aimed to demonstrate the effects of porosity variation with 
geochemical mineral reactions. Indeed, the implementation requires further exploration, validation and application; nevertheless, the preliminary investigation presented, indicate a coupling scheme between porosity and geochemistry has been built in the model.

\section{Conclusions}

The modelling developments presented via the inclusion of the PHREEQC model to the coupled THCM model (COMPASS) offers an extensive capability to study various aspects of physical, chemical and mechanical behaviour of unsaturated soils. The developed reactive transport model, benefits from the advances both in the transport formulation under coupled THCM framework and in the reaction module where PHREEQC provides a wide range capabilities for geochemical reaction modelling. The capability of the geochemical model to analyse mixed equilibrium and kinetically controlled chemical reactions, various homogeneous and heterogeneous reactions such as mineral reactions, ion exchange, and high concentration ionic solutions are among the key advantages of the new THCM model.

In a series of simulations, the coupling of the geochemical reaction model with transport model, i.e. COMPASS-PHREEQC was tested against various benchmarks. Close correlations between the results of the developed model in comparison with the benchmarks, have supported the accuracy of the implementation of the theoretical formulations and numerical implementation. The results indicated that the numerical solution (adopted to solve the governing equations for flow), and the sequential scheme, (implemented to solve the governing equations for reactive transport of chemicals), provides an efficient solution for the problems considered.

An important development was initiated to couple the chemical/geochemical with porosity variation and flow properties in the theoretical basis of the model. Accordingly the effects of mineral precipitation/dissolution on flow parameters were implemented as a porosity modification feedback 
from the geochemical model. In other words, flow properties such as hydraulic conductivity, were modified due to variation in porosity with mineral precipitation or dissolution.

\section{Acknowledgement}

The financial support received through a PhD Fellowship by the first author under the Overseas Research Students Award Scheme (ORSAS) is gratefully acknowledged. The support and contribution in the early stages of this work from Dr. Suresh Seetharam; a former Research Fellow at the Geoenvironmental Research Centre is gratefully acknowledged.

\section{References}

Engersgaard, P., and Kipp, K.L. 1992. A geochemical transport model for redox-controlled movement of mineral fronts in groundwater flow systems: A case of nitrate removal by Oxidation of Pyrite. Water Resources Research, 28(10), 2829-2843.

Guimarães, L.D.N., Gens, A., and Olivella, S. 2007. Coupled thermo-hydro-mechanical and chemical analysis of expansive clay subjected to heating and hydration. Transport in Porous Media, 66, 341372.

Jacques, D., and Šimůnek, J. 2005. User manual of the Multicomponent Variably-Saturated Flow and Transport Model HP1. Description, verification, and examples. Version 1.0. BLG-998 Rep. SCKECEN, Mol, Belgium.

Lasaga, A.C. 1998. Kinetic Theory in the Earth Science. Princeton Series in Geochemistry, Princeton University Press.

Millington, R.J., and Quirk, J.M. 1961. Permeability of porous solids. Transaction Faraday Society, 57, $1200-1207$. 
Parkhurst, D.L., and Appelo, C.A.J. 1999. User's Guide to PHREEQC (version 2), U.S. Geological Survey, Water Resource Investigation Report, 99-4259.

Prommer, H., Barry, D.A., and Davis, G.B. 2002. Modelling of physical and reactive processes during biodegradation of a hydrocarbon plume under transient groundwater flow conditions. Journal of Contaminant Hydrology, 59, 113-131.

Samper, J., Xu, T., and Yang, C. 2009. A sequential partly iterative approach for multicomponent reactive transport with $\mathrm{CORE}^{2 \mathrm{D}}$. Computers and Geosciences, 13, 301-316.

Sedighi, M. 2011. An investigation of hydro-geochemical processes in coupled thermal, hydraulic, chemical and mechanical behaviour of unsaturated soils. Ph.D. Thesis, Cardiff University, UK

Sedighi, M., Thomas, H.R., and Vardon, P.J. 2011. Modelling thermal impacts on reactive transport processes related to multicomponent chemicals in compacted clays. The $2^{\text {nd }}$ International Symposium on Computational Geomechanics (ComGeo II), 538-546.

Seetharam, S.C., Thomas, H.R., and Cleall, P.J. 2007. Coupled thermo-hydro-chemical-mechanical model for unsaturated soils-Numerical algorithm. International Journal of Numerical Methods in Engineering, 70, 1480-1511.

Šimůnek, J., van Genuchten, M. Th., and Šejna, M. 2008. The HYDRUS-1D software package for simulating the one-dimensional movement of water, heat, and multiple solutes in variably-saturated media. Version 4.0. HYDRUS Software Service 3. Department of Environmental Sciences, University of California, Riverside.

Steefel, C.I. and Lasaga, A.C. 1994. A coupled model for transport of multiple chemical species and kinetic precipitation/dissolution reactions with application to reactive flow in single phase hydrothermal systems. American Journal of Science, 294, 529-592. 
Steefel, C.I., and MacQuarrie, K.T.B. 1996. Approaches to modeling of reactive transport in porous media. Reactive Transport in Porous Media, Reviews in Mineralogy, (34). Mineralogical Society of America, Washington, DC.

Steefel, C.I., and Maher, K. 2009. Fluid-rock interaction, A reactive transport Approach. Thermodynamics and Kinetics of Water-Rock Interaction, Reviews in Mineralogy and Geochemistry, (70), 485-532.

Thomas, H.R., and He, Y. 1998. Modelling the behaviour of unsaturated soil using an elasto-plastic constitutive relationship. Géotechnique, 48(5), 589-603.

Thomas, H.R., Sedighi, M., and Vardon, P.J. 2012. Diffusive reactive transport of multicomponent chemicals under coupled thermal, hydraulic, chemical and mechanical conditions, Geotechnical and Geological Engineering, 30(4), 841-857.

Wissmeier, L., and Barry, D.A. 2008. Reactive transport in unsaturated soil: comprehensive modelling of the dynamic spatial and temporal mass balance of water and chemical components. Advances in Water Resources, 31 (5), 858-875.

$\mathrm{Xu}, \mathrm{T}$. , and Pruess, K. 1998. Coupled modeling of non-isothermal multiphase flow, solute transport and reactive chemistry in porous and fractured media: 1. Model development and validation. Lawrence Berkeley National Laboratory Report, LBNL-42050, Berkeley, California.

Xu, T., Samper, J., Ayora, C., Manzano, M., and Emilio, C. 1999. Modeling of non-isothermal multicomponent reactive transport in field scale porous media flow systems. Journal of Hydrology, 214, 144-164. 


\section{List of Tables}

Table 1. Material parameters and relationships used for the simulation of Test I-a, I-band I-c.

Table 2. Material parameters and relationships used for the simulation of Test II.

Table 3. Material parameters and relationships used for the simulation of Test III.

Table 4. Material parameters and relationships used for the simulation of porosity feedback effect on chemical behaviour. 


\section{Figure Captions}

Figure 1. The sequential non-iterative approach (SNIA) adopted for coupling the transport model (COMPASS) and geochemical model (PHREEQC).

Figure 2. Concentration of the dissolved ions after 5 days analysis (equilibrium mineral reaction analysis) from the numerical modelling (lines) and analytical solution (symbols).

Figure 3. Chemical concentration profiles at steady-state under kinetically controlled condition analysed by the numerical model (lines) and the analytical solution (symbols).

Figure 4. Chemical concentration profiles after five days of analysed by the numerical model; using different kinetic rates of reaction (lines) and under equilibrium reaction (symbols).

Figure 5. The concentration profiles of dissolved chemical components after 21,000 seconds of analysis.

Figure 6. Discharge of the dissolved chemical concentrations at different pore volumes at the boundary, calculated by the numerical model (solid lines) and by PHREEQC version 2.15 (symbols).

Figure 7. Numerical model prediction of the exchanger composition at different pore volumes.

Figure 8. Transient profiles of the precipitate mineral obtained from i) the numerical simulation with considering porosity feedback from geochemistry (lines) and ii) the analysis without the effect (symbols).

Figure 9. Transient profiles of the dissolved chemicals from i) the numerical analysis with considering porosity feedback from geochemistry (lines) and ii) the analysis without the effect (symbols).

Figure 10. Transient profiles of the volume of the precipitated mineral, obtained from the numerical analysis. 


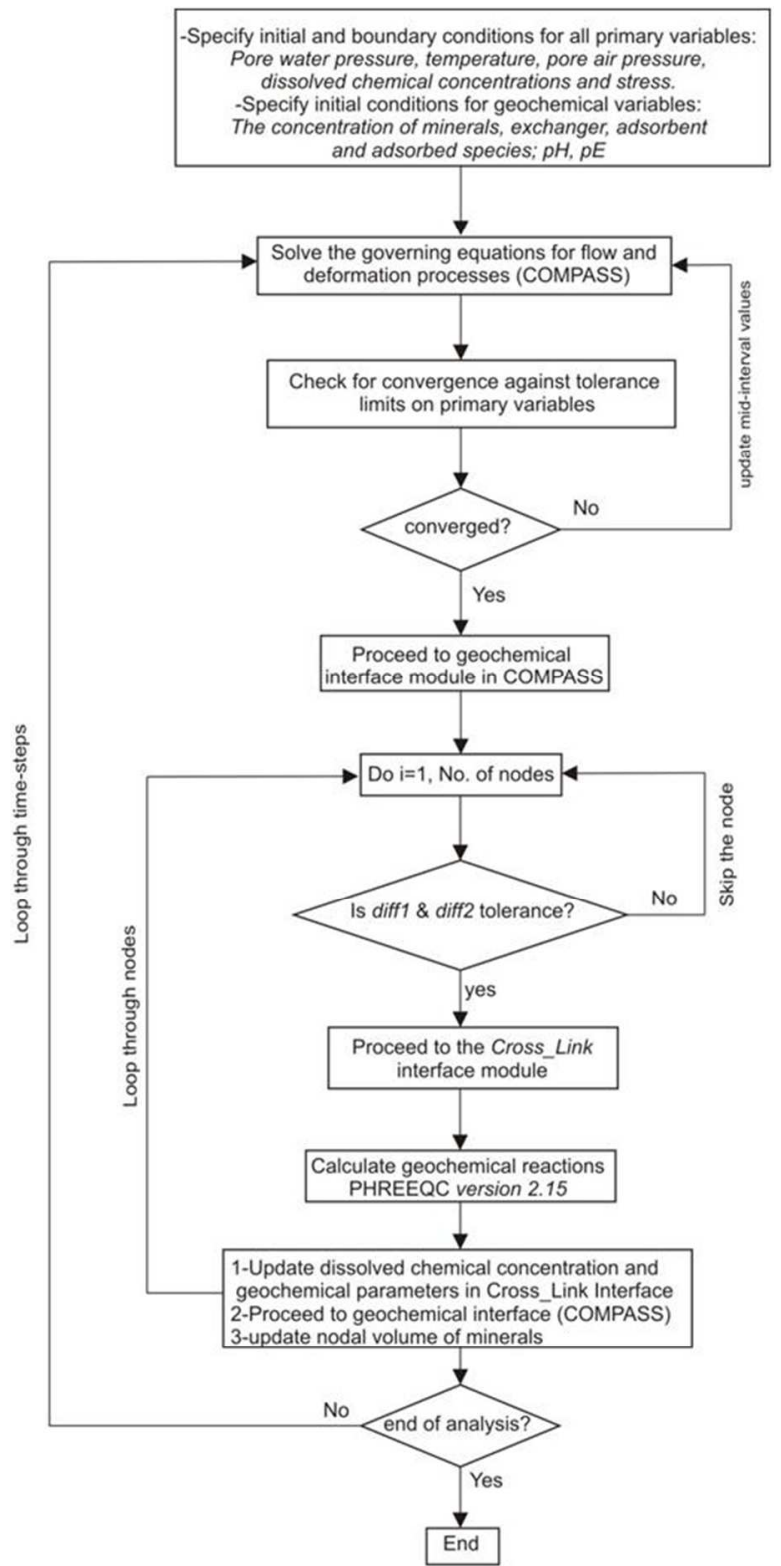

Figure 1. The sequential non-iterative approach (SNIA) adopted for coupling the transport model (COMPASS) and geochemical model (PHREEQC). $86 \times 177 \mathrm{~mm}(150 \times 150 \mathrm{DPI})$ 


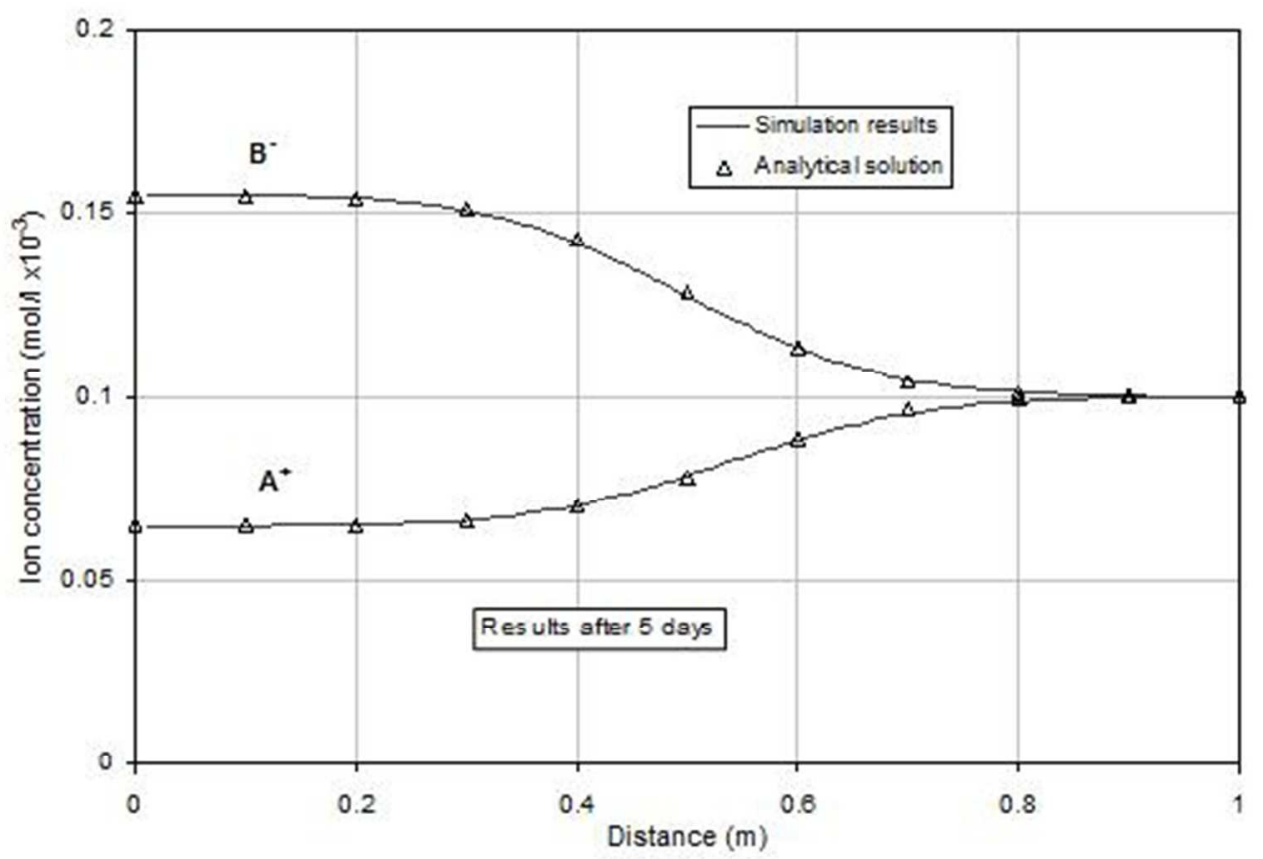

Figure 2. Concentration of the dissolved ions after 5 days analysis (equilibrium mineral reaction analysis) from the numerical modelling (lines) and analytical solution (symbols). $86 \times 59 \mathrm{~mm}(150 \times 150$ DPI $)$ 


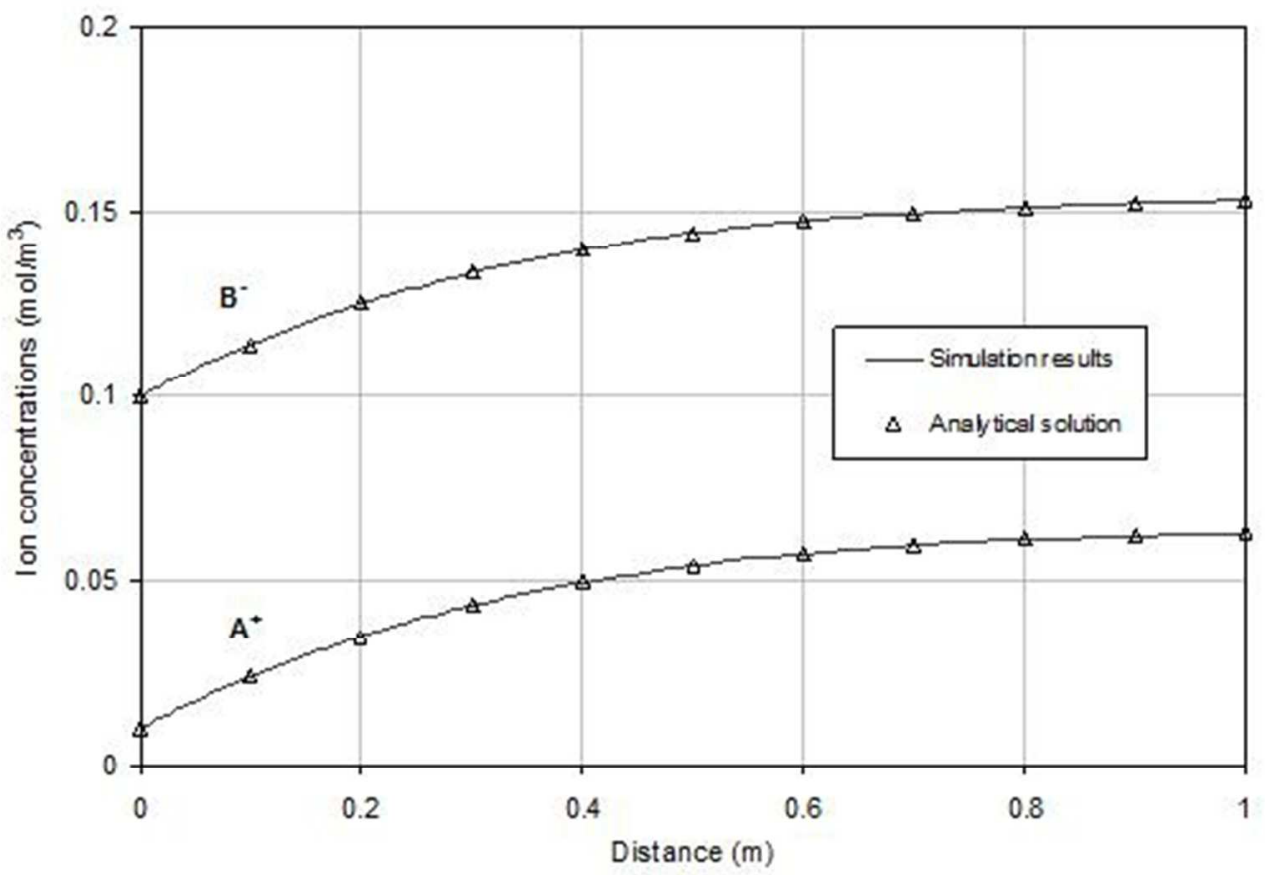

Figure 3. Chemical concentration profiles at steady-state under kinetically controlled condition analysed by the numerical model (lines) and the analytical solution (symbols). $86 \times 60 \mathrm{~mm}(150 \times 150 \mathrm{DPI})$ 


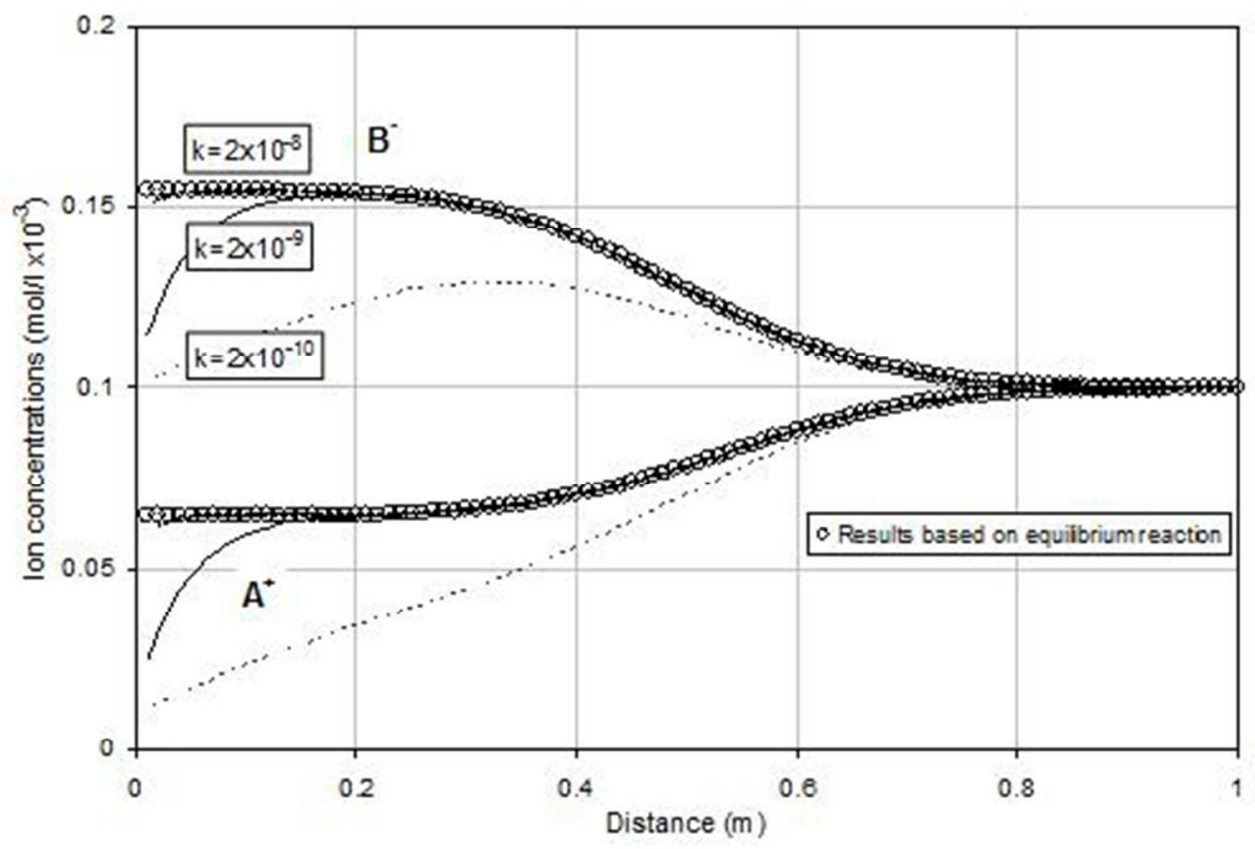

Figure 4. Chemical concentration profiles after five days of analysed by the numerical model; using different kinetic rates of reaction (lines) and under equilibrium reaction (symbols). $86 \times 59 \mathrm{~mm}(150 \times 150$ DPI $)$ 


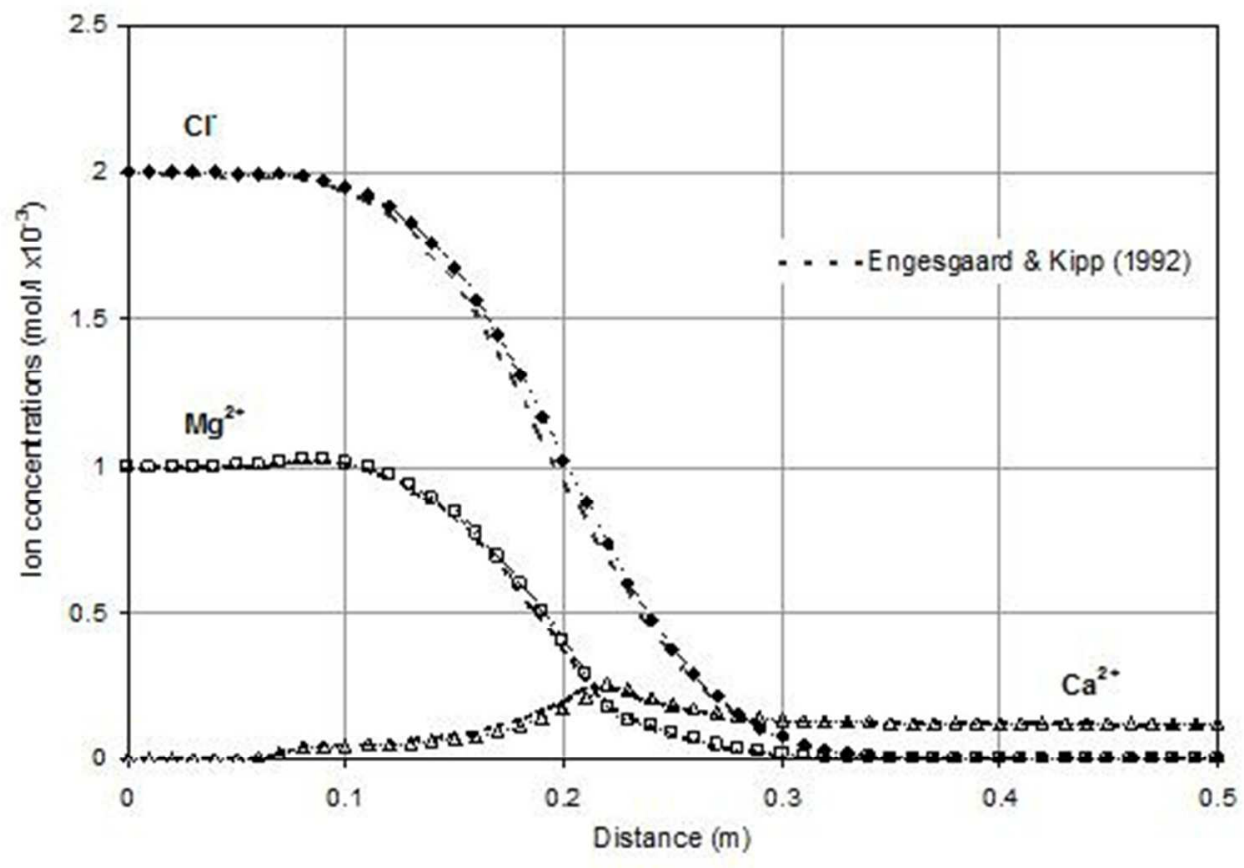

Figure 5. The concentration profiles of dissolved chemical components after 21,000 seconds of analysis. $86 \times 59 \mathrm{~mm}(150 \times 150 \mathrm{DPI})$ 


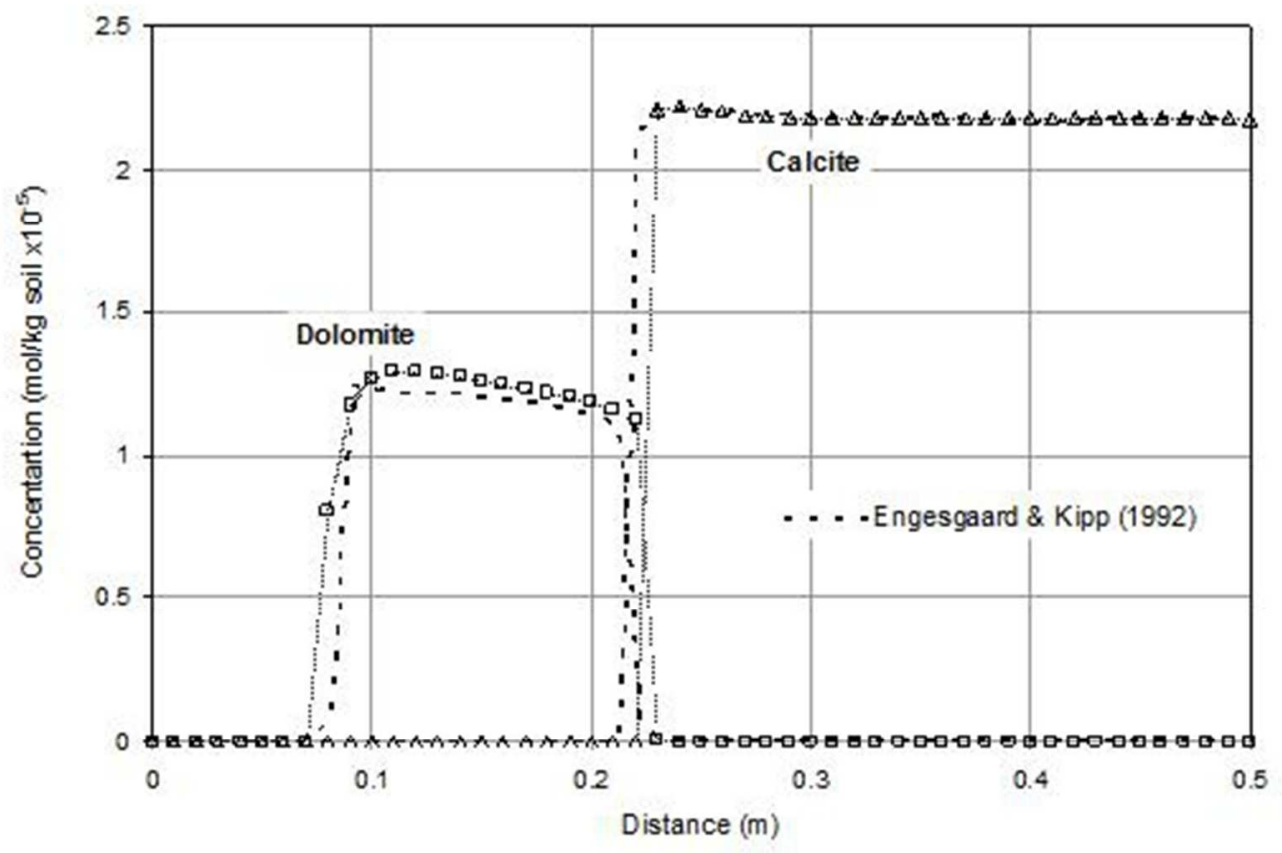

Figure 6. Discharge of the dissolved chemical concentrations at different pore volumes at the boundary, calculated by the numerical model (solid lines) and by PHREEQC version 2.15 (symbols).

$86 \times 60 \mathrm{~mm}(150 \times 150 \mathrm{DPI})$ 


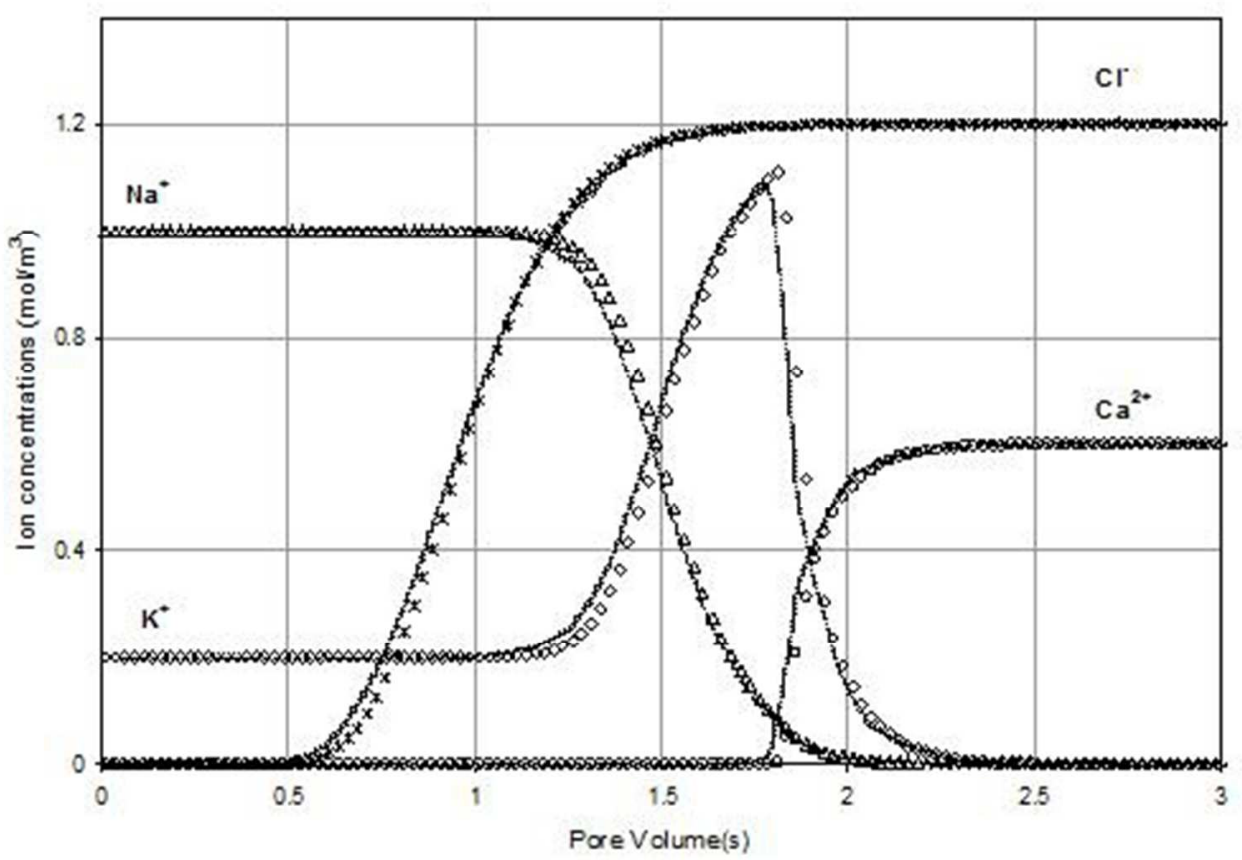

Figure 7. Numerical model prediction of the exchanger composition at different pore volumes. $86 \times 63 \mathrm{~mm}(150 \times 150 \mathrm{DPI})$ 


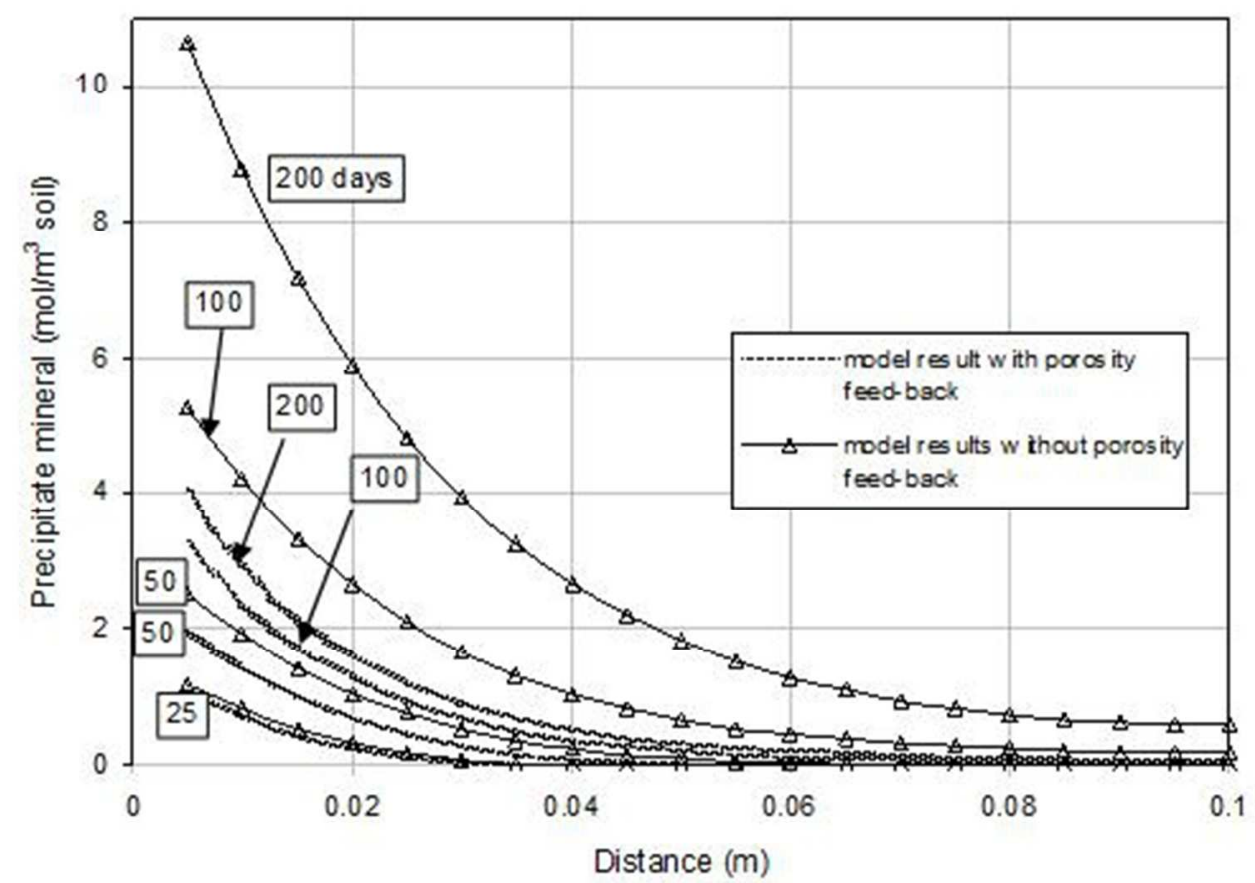

Figure 8. Transient profiles of the precipitate mineral obtained from i) the numerical simulation with considering porosity feedback from geochemistry (lines) and ii) the analysis without the effect (symbols). $86 \times 65 \mathrm{~mm}(150 \times 150 \mathrm{DPI})$ 


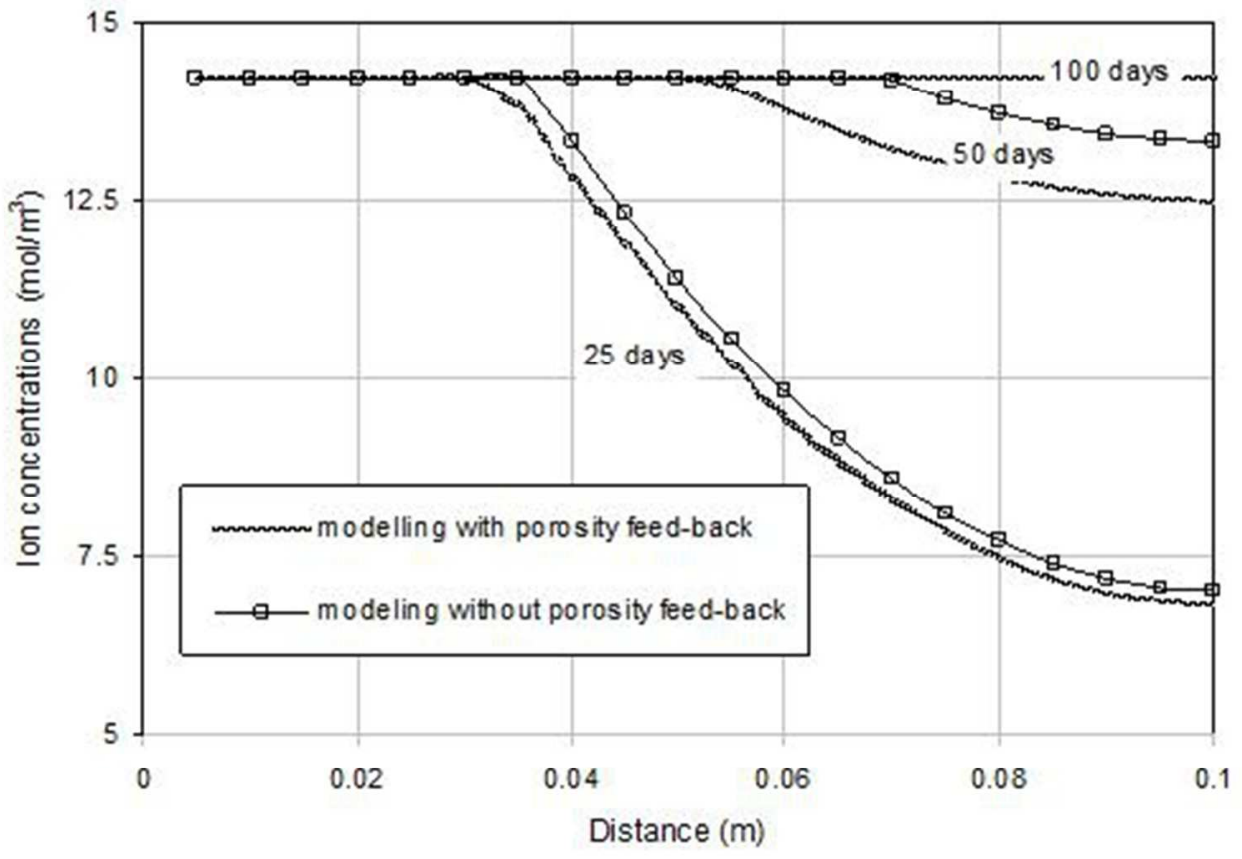

Figure 9. Transient profiles of the dissolved chemicals from i) the numerical analysis with considering porosity feedback from geochemistry (lines) and ii) the analysis without the effect (symbols). $86 \times 62 \mathrm{~mm}(150 \times 150 \mathrm{DPI})$ 


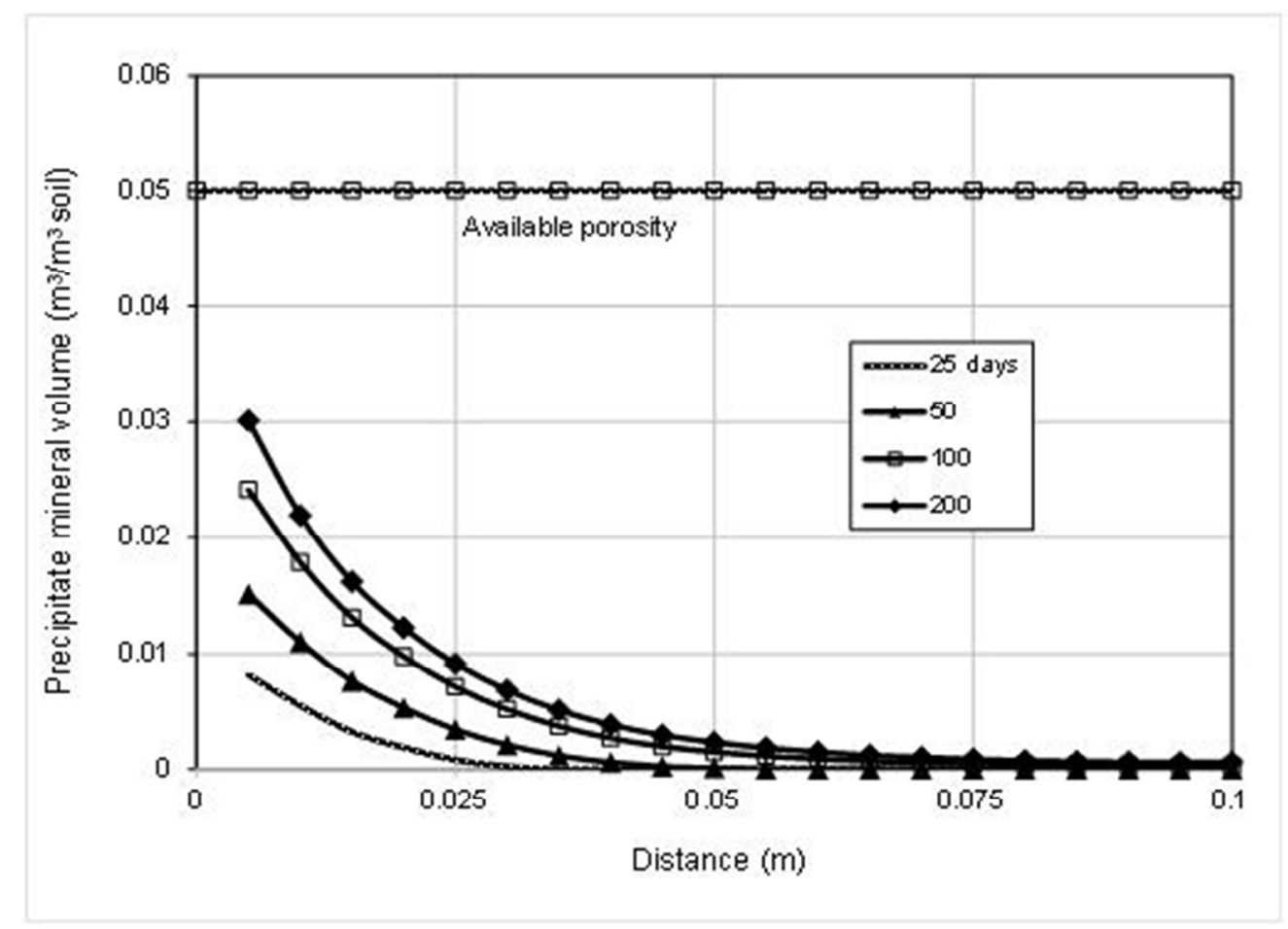

Figure 10. Transient profiles of the volume of the precipitated mineral, obtained from the numerical analysis. $86 \times 62 \mathrm{~mm}(150 \times 150$ DPI $)$ 
Table 1. Material parameters and relationships used for the simulation of Test I-a, I-b and I-c.

\begin{tabular}{|c|c|}
\hline & Relationship/value \\
\hline Porosity & $n=0.4$ \\
\hline Degree of saturation & $S_{l}=1.0$ \\
\hline Pore water velocity & $V_{l}=0.1 \mathrm{~m} / \mathrm{day}$ \\
\hline Hydraulic conductivity & $k_{l}=1.1 \times 10^{-4} \mathrm{~m} / \mathrm{s}$ \\
\hline Diffusion coefficient of chemicals & $D_{i}=0$ \\
\hline Longitudinal dispersion coefficient & \\
\hline $\begin{array}{l}\text { (Only used for simulations under equilibrium reactions Test I-a and I- } \\
\text { c) }\end{array}$ & $\alpha_{L}=0.02$ \\
\hline Equilibrium constant of reaction $A B_{s}=A^{+}+B^{-}$ & $\begin{array}{l}\log K_{e q}=-8.0 \\
\text { (at } 25^{\circ} \mathrm{C} \text { ) }\end{array}$ \\
\hline
\end{tabular}


Table 2. Material parameters and relationships used for the simulation of Test II

\begin{tabular}{lll}
\hline & Relationship/value \\
\hline Porosity & $n=0.32$ & \\
Pore water velocity & $V_{l}=9.37 \times 10^{-6} \mathrm{~m} / \mathrm{s}$ \\
Hydraulic conductivity & $k_{l}=1.1 \times 10^{-4}$ & $\mathrm{~m} / \mathrm{s}$ \\
Diffusion coefficient of chemicals & $D_{i}=0$ & $\mathrm{~m} / \mathrm{s}$ \\
Dispersivity coefficient $\left(\right.$ Longitudinal) $^{2}$ & $\alpha_{L}=0.0067$ & $\mathrm{~m}$ \\
$\begin{array}{l}\text { Equilibrium constant of reactions }\left(\text { at } 25{ }^{\circ} \mathrm{C}\right) \\
\mathrm{CaCO}_{3}(\mathrm{~s})=\mathrm{Ca}^{2+}+\mathrm{CO}_{3}{ }^{2-}\end{array}$ & $\log K_{\text {eq }}=-8.47$ & \\
$\mathrm{CaMg}\left(\mathrm{CO}_{3}{ }^{2-}\right)_{2}(\mathrm{~s})=\mathrm{Ca}^{2+}+\mathrm{Mg}^{2+}+2 \mathrm{CO}_{3}{ }^{2-}$ & $\log K_{e q}=-17.7$ & \\
\hline
\end{tabular}


Table 3. Material parameters and relationships used for the simulation of Test III

\begin{tabular}{ll}
\hline & Relationship/value \\
\hline Porosity & $n=1.0$ \\
Pore water velocity & $V_{l}=1.0 \mathrm{~m} /$ day $=1.157 \times 10^{-5} \mathrm{~m} / \mathrm{s}$ \\
Hydraulic conductivity & $k_{l}=1.157 \times 10^{-5} \quad \mathrm{~m} / \mathrm{s}$ \\
Diffusion coefficient of chemicals & $D_{i}=0 \quad: \mathrm{m}^{2} / \mathrm{s}$ \\
Dispersivity coefficient (Longitudinal) & $\alpha_{L}=0.002 \quad \mathrm{~m}$ \\
Equilibrium constant of reactions (at $\left.25^{\circ} \mathrm{C}\right)$ & \\
$\mathrm{Na}-\mathrm{X}=\mathrm{Na}^{+}+\mathrm{X}$ & $\log K_{e q}=0.0$ \\
$\mathrm{~K}-\mathrm{X}=\mathrm{K}^{+}+\mathrm{X}^{-}$ & $\log K_{e q}=0.7$ \\
$\mathrm{Ca}-\mathrm{X}_{2}=\mathrm{Ca}^{2+}+2 \mathrm{X}$ & $\log K_{e q}=0.8$ \\
\hline
\end{tabular}


Table 4. Material parameters and relationships used for the simulation of porosity feedback effect on chemical behaviour.

\begin{tabular}{ll}
\hline \multicolumn{1}{c}{ Relationship/value } \\
\hline Porosity & $n=0.05$ \\
Degree of saturation & $S_{l}=1.0$ \\
Hydraulic conductivity & $K_{\text {sat }}=1.0 \times 10^{-13} \mathrm{~m} / \mathrm{s}$ \\
Tracer diffusion coefficient of chemicals in water & $D^{0}\left(A^{+}\right)=D^{0}\left(B^{-}\right)=10 \times 10^{-10} \mathrm{~m}^{2} / \mathrm{s}$ \\
\hline Equilibrium constant of reactions $\left(\right.$ at $\left.25^{\circ} \mathrm{C}\right) A B s=A^{+}+B^{-}$ & $\log K_{e q}=-4.64$ \\
\hline
\end{tabular}

